\title{
Pengaruh Reputasi Koperasi terhadap Kepercayaan Anggota Koperasi
}

\section{(Studi Kasus Pada Unit Usaha Peternak Sapi KSU Tandangsari Sumedang)}

The Influence of Cooperative Reputation to Trust in Cooperative Members

(Case Study of Tandangsari Sumedang KSU Cow Farmer Business Unit)

\author{
Agus Arifin \\ Institut Koperasi Indonesia \\ Deagus42@gmail.com \\ Mukhammad Ridwan \\ Institut Koperasi Indonesia \\ mukhammadridwanmurid@gmail.com
}

\section{Itah Bella Permana}

Institut Koperasi Indonesia|

Bellapermana1408@gmail.com

\section{Euis Widianti}

Institut Koperasi Indonesi

Widiantieuis08@gmail.com

\section{Iva Lathifah}

Institut Koperasi Indonesia

Lathifah61@gmail.com

\begin{abstract}
Abstrak The importance of loyalty from all members to the cooperative by paying attention to the reputation of the cooperative and the trust of its members. The purpose of this study was to find out how the influence of Cooperative Reputation (X) on Cooperative Member Trust (Y) in the KSU TandangSari Sumedang dairy farming business unit. This research is quantitative research. The population is all members of the business unit dairy farmer KSU Tandangsari Sumedang, using a random sampling method involving 42 respondents. Data collection uses questionnaires (questionnaires) and interviews with answers based on the guttman scale "YES" or "NO". Data analysis using correlation regression analysis with previous hypothesis testin. The results of this study indicate that the reputation of cooperatives has a strong influence on the trust of cooperative members in the KSU TandangSari Sumedang dairy farming business unit.
\end{abstract}


Keywords cooperative reputation, member trust, and loyalty of members of cow farmers.

\section{Pendahuluan}

Dalam dunia usaha di Indonesia tidak dapat mengelak dari pengaruh era globalisasi. Dalam era ini tingkat ketergantungan antar bangsa semakin meningkat. Pesatnya perkembangan ilmu pengetahuan, teknologi dan informasi mendorong terjadinya perdagangan bebas dimana dunia akan semakin transparan dan semakin tanpa batas.

Dampak dari globalisasi ini sendiri sudah memasuki hampir seluruh aspek kehidupan masyarakat di dunia. Akibatnya peta kekuatan ekonomi dari iklim dunia usaha diwarnai dengan persaingan yang semakin ketat. Salah satu dampaknya adalah merambahnya bisnis usaha dari skala besar hingga skala kecil yang dilakukan oleh usaha swasta juga koperasi.

Koperasi merupakan salah satu badan usaha yang dipilih oleh sebagian masyarakat dalam rangka meningkatkan taraf hidupnya. Selain koperasi, terdapat badan usaha lainnya yang memiliki sifat dan ciri yang berbeda dengan koperasi. Salah satu ciri yang membedakan koperasi adalah dasar falsafahnya. Dasar falsafah koperasi untuk mencapai kesejahteraan bersama berdasarkan asas kekeluargaan sedangkan dasar falsafah badan usaha bukan koperasi untuk mencapai laba sebesar-besarnya.

MenurutUndang-Undang Republik Indonesia No. 17 Tahun 2012 tentang Perkoperasian pasal 2: "koperasi didirikan dengan tujuan utamanya untuk mensejahterakan rakyat Indonesia serta ikut membangun tatanan ekonomi nasional", peran koperasi di Indonesia sangat dibutuhkan, karena koperasi memiliki karakteristik yang hampir sama dengan kondisi masyarakat Indonesia yang bersahaja, adanya koperasi di tengah masyarakat akan memberikan dampak positif bagi pertumbuhan ekonomi, karena dengan adanya unit-unit usaha yang dijalankan oleh koperasi otomatis roda perekonomian pun akan menggeliat, sehingga pada masa pembangunan ini koperasi sangat besar sekali peranannya dalam sektor kehidupan perekonomian bangsa Indonesia. Oleh karena itu sumber daya manusia pada setiap koperasi harus di perhatikan agar sumber daya manusia yang ada dalam koperasi selalu senantiasa terjaga, baik kesehatan, kompensasi ataupun kinerja sumber daya yang ada dalam koperasitersebut.

Koperasi Serba Usaha Tandangsari yang beralamat di belakang pasar Tanjungsari No.29 Desa Jatisari Sumedang, tercatat dalam badan hukum No 7251/BH/PAD/DK.10.13/III/2002 didirikan pada tanggal 26 Januari 1981 dalam menjalankan kegiatannya KSU Tandangsari dikelola oleh lima orang pengurus, tiga orang pengawas dan 77 orang karyawan serta beranggotakan 2.365orang pada akhir tahun 2018 .

Adapun unit usaha yang dijalankan oleh KSU Tandangsari antara lain :

- Unit usaha perternakan sapi perah 
- Unit usaha pakan ternak dan Sapronak (sarana produksi peternakan)

- Unit usaha simpanpinjam

Berdasarkan Laporan Pertanggungjawaban Pengurus Koperasi Serba Usaha Tandangsari Sumedang Tahun Buku 2018. Jumlah anggota pada dua tahun terakhir (2017-2018) mengalami penurunan sejumlah 717 orang.

Tabel 1.1 Data Perkembangan Anggota Tahun 2017-2018

\begin{tabular}{|c|c|}
\hline Keterangan & Jumlah Anggota \\
\hline Jumlah Anggota Akhir Tahun 2017 & $\mathbf{2 . 3 9 2}$ \\
\hline Masuk selama Tahun 2018 & 171 \\
\hline Keluar atas Permohonan Sendiri & $\mathbf{7 1 7}$ \\
\hline Meninggal & 21 \\
\hline Jumlah Anggota Akhir Tahun 2018 & $\mathbf{2 . 3 6 5}$ \\
\hline
\end{tabular}

Sumber: Laporan RAT KSU Tandangsari Sumedang

Dari tabel 1.1 terlihat bahwa anggota KSU Tandangsari mengalami penurunan anggota di tahun 2018 dengan jumlah 717 orang dengan keterangan keluar atas permohonan sendiri dari jumlah 2.932 orang anggota tahun 2017. Maka dari itu kami melakukan penelitian tentang anggota yang mengundurkan diri sebagai anggota KSU Tandangsari Sumedang yang cukup banyak di tahun 2018 mengapa hal ini dapat terjadi dan kami memperdalam tentang kepercayaan anggota terhadap koperasi khususnya pada Unit Usaha PeternakSapi.

Pengertian ini dilakukan untuk mengetahui pengaruh dari reputasi anggota terhadap kepercayaan anggota peternak sapi KSU Tandangasari.

\section{Metode Penelitian}

\section{Rancangan penelitian}

Penelitian ini merupakan jenis penelitian kuantitatif.

\section{Jenis dan sumber data}

Penelitian ini menggunakan data primer dan data sekunder. Data primer pada penelitian ini adalah data mengenai pendapat/persepsi/pengalaman tentang pengaruh dari reputasi anggota terhadap kepercayaan anggota peternak sapi KSU Tandangasari. Data sekunder pada penelitian ini adalah data jumlah anggota peternak dan data yang berhubungan dengan KSU Tandangsari. Sumber data primer pada penelitian diperoleh dari responden yakni anggota 
peternak sapi KSU Tandangsari. Sumber data sekunder diperoleh dari Sekretaris KSU Tandangsari yakni Dr.Suwarni.

\section{Populasi dan sampel}

Populasi pada penelitian ini terdiri atas seluruh anggota peternak sapi KSU Tandangsari yang berjumlah 840 anggota. Pengambilan sampel menggunakan teknik rabdom acak sampling, dengan kriteria anggota yang menjadi peternak susu sapi. Total jumlah responden penelitian ini adalah sebanyak 42 anggota.

\section{Metode analisis data}

Metode analisis yang digunakan adalah uji asumsi klasik. Uji ini memiliki jenis uji linearitas dan uji hipotesis. Uji hipotesis yang digunakan meliputi analisis regresi korelasi, uji $\mathrm{t}$, uji F, dan uji koefisien determinasi.

\section{Hasil Penelitian}

\section{Uji Asumsi Klasik}

\section{Uji Normalitas}

Uji normalitas digunakan untuk mengetahui apakah populasi data berdistribusi normal atau tidak. Untuk menguji apakah distribusi data normal atau tidak, digunakan uji statistik non parametik Kolmogorov Smimov $(K-S)$ dan uji grafik p-plot. Data yang terdistribusi normal ditunjukkan dengan nilai signifikansi $>0,05$ atau 5\% untuk uji statistik dan titik-titik plot tersebar di sekitar garis diagonal untuk uji grafik p-plot. Hasil pengujian normalitas dapat dilihat pada tabel dan gambar berikut:

Tabel 1. Hasil Uji Normalitas Kolmogorov Smirnov $(K-S)$

\begin{tabular}{|l|l|r|}
\hline \multicolumn{2}{|l|}{ One-Sample Kolmogorov-Smirnov Test } \\
\hline \multicolumn{2}{|l|}{} & Unstandardized Predicted Value \\
\hline \multirow{2}{*}{ N } & 42 \\
\hline \multirow{2}{*}{ Normal Parameters ${ }^{\mathrm{ab}}$} & Mean & 13,6904762 \\
\cline { 2 - 3 } & Std. Deviation &, 22316619 \\
\hline \multirow{2}{*}{ Most Extreme Differences } & Absolute &, 263 \\
\cline { 2 - 3 } & Positive &, 225 \\
\cline { 2 - 3 } & Negative &,- 263 \\
\hline Test Statistic & &, 263 \\
\hline Asymp. Sig. (2-tailed) & &, 000 \\
\hline
\end{tabular}


a. Test distribution is Normal.

b. Calculated from data.

c. Lilliefors Significance Correction.

Berdasarkan tabel 1, dapat diketahui bahwa nilai di atas menunjukan nilai Kolmogorv-Smirnov variabel reputasi koperasi adalah sebesar 0,263 dengan probabilitas signifikansi 0,200 dan nilai Kolmogorv-Smirnov variabel kepercayaan anggota adalah sebesar 0,175 dengan probabilitas signifikansi 0,092. Kedua nilai signifikansi yang diperoleh lebih besar $\alpha=0,05(0,200$ dan $0,092>0,05)$. Hal tersebut berarti hipotesis nol diterima dengan arti bahwa kedua variabel terdistribusi normal dan kedua variabel penelitian telah memenuhi asumsi normalitas. Kemudian, dibawah ini merupakan hasil uji normalitas dengan uji grafik p-plot :

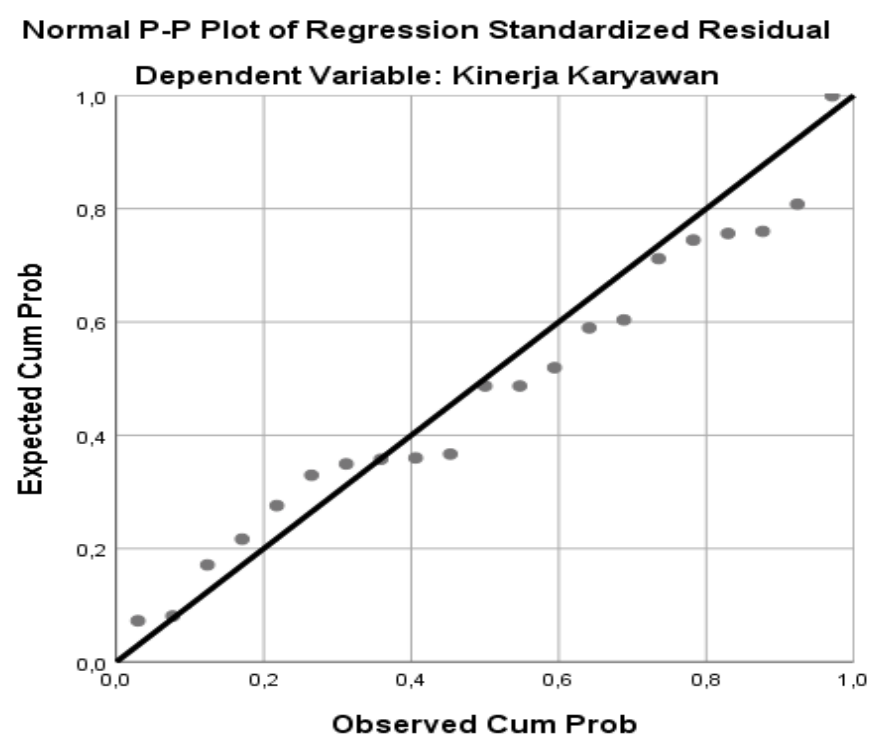

\section{Gambar 1. Hasil Uji Normalitas Grafik P-Plot}

Dengan melihat tampilan gambar grafik normal p-plot dapat disimpulkan bahwa grafik normal p-plot terlihat titik - titik menyebar di sekitar garis diagonal. Grafik tersebut menunjukkan bahwa model regresi telah memenuhi asumsi normalitas.

\section{Uji Linearitas}

Penelitian ini menggunakan teknik analisis bivariat untuk melihat ada tidaknya hubungan antara reputasi koperasi dengan kepercayaan anggota dari data yang diperoleh serta untuk melihat seberapa kuat hubungan di antara kedua variabel tersebut. Dalam penelitian ini, variabel independennya adalah reputasi koperasi sementara variabel dependennya adalah kepercayaan anggota. Tahap pertama dalam melakukan analisis regresi linier adalah melakukan analisis faktor terhadap indikator yang terpilih menjadi bentuk faktor skor. Tahap kedua melakukan estimasi dari faktor skor yang diperoleh dengan analisis single regression 
dengan bantuan SPSS versi 25.0. Hasil keluarannya berupa uji F dan tingkat signifikansi yang terdapat pada tabel ANOVA. Sedangkan uji t dan tingkat signifikansi terdapat pada tabel coefficient yang keduanya digunakan untuk membentuk signifikansi pengaruh masing-masing konstruk. Analisis regresi linier digunakan untuk menguji rangkaian pengaruh antara satu variabel independen dengan satu variabel dependen. Reputasi koperasi dalam penelitian ini adalah variabel independen dan yang menjadi variabel depeden adalah kepuasan kerja. Hipotesis dalam penelitian ini adalah:

$\mathrm{H}_{0}$ : Reputasi Koperasi tidak memberikan pengaruh terhadap Kepercayaan Anggota pada Koperasi Serba Usaha Tandangsari Sumedang

$\mathrm{H}_{\mathrm{a}}$ : Reputasi Koperasi memberikan pengaruh terhadap kepercayaan anggota pada Koperasi Serba Usaha Tandangsari Sumedang

Pengujian linearitas dapat dilihat dari hasil output Test of Linearity pada taraf signifikansi 0,05 pada program SPSS. Dua variabel dikatakan mempunyai hubungan yang linear bila taraf signifikansi kurang dari 0,05. Berikut hasil pengujian linearitas antara variabel kepuasan kerja dengan variabel kinerja karyawan :

\begin{tabular}{|c|c|c|c|c|c|c|c|}
\hline \multicolumn{8}{|c|}{ ANOVA Table } \\
\hline & & & $\begin{array}{l}\text { Sum of } \\
\text { Squares }\end{array}$ & df & $\begin{array}{l}\text { Mean } \\
\text { Square }\end{array}$ & $\mathrm{F}$ & Sig. \\
\hline \multirow{5}{*}{$\begin{array}{l}\text { Kinerja } \\
\text { Karyawan } \\
* \\
\text { Kepuasan } \\
\text { Kerja }\end{array}$} & \multirow[t]{3}{*}{$\begin{array}{l}\text { Between } \\
\text { Groups }\end{array}$} & (Combined) & 3023,200 & 11 & 274,836 & 17,241 & ,000 \\
\hline & & Linearity & 2296,656 & 1 & 2296,656 & 144,075 & ,000 \\
\hline & & $\begin{array}{l}\text { Deviation } \\
\text { from } \\
\text { Linearity }\end{array}$ & 726,544 & 10 & 72,654 & 4,558 & ,016 \\
\hline & \multicolumn{2}{|c|}{ Within Groups } & 143,467 & 9 & 15,941 & & \\
\hline & \multicolumn{2}{|l|}{ Total } & 3166,667 & 20 & & & \\
\hline
\end{tabular}

Berdasarkan hasil pengujian linearitas tersebut dapat diketahui nilai signifikansi linearitas antara variabel kepuasan kerja dengan variabel kinerja karyawan sebesar 0,000lebih kecil dari taraf signifikansi 0,05 , maka dapat disimpulkan $\mathrm{H}_{0}$ ditolak, artinya variabel kepuasan kerja dengan variabel kinerja karyawanmempunyai hubungan yang linear. 


\section{Analisis Regresi Linear Berganda}

Tabel dibawah ini merupakan hasil analisis regresi linear sederhana antara variabel kepuasan kerja terhadap variabel kinerja karyawan :

Tabel 3. Hasil Analisis Regresi Linear Sederhana

\begin{tabular}{|c|c|c|c|c|c|c|}
\hline \multicolumn{7}{|c|}{ Coefficients $^{a}$} \\
\hline & & \multicolumn{2}{|c|}{$\begin{array}{l}\text { Unstandardized } \\
\text { Coefficients }\end{array}$} & \multirow{2}{*}{$\begin{array}{c}\begin{array}{c}\text { Standardized } \\
\text { Coefficients }\end{array} \\
\text { Beta }\end{array}$} & \multirow[b]{2}{*}{$\mathrm{T}$} & \multirow[b]{2}{*}{ Sig. } \\
\hline \multicolumn{2}{|c|}{ Model } & B & Std. Error & & & \\
\hline \multirow[t]{2}{*}{1} & (Constant) & 10,839 & 1,046 & & 10,359 & ,000 \\
\hline & Reputasi & 258 & ,094 & 397 & 2,733 & ,009 \\
\hline
\end{tabular}

a. Dependent Variable: kepercayaan

Nilai - nilai untuk persamaan regresi linear sederhana dapat dilihat pada tabel di atas sehingga dapat diperoleh persamaan sebagai berikut:

$$
Y=10,839+0,258 X
$$

Pada tabel koefisien di atas, nilai koefisien regresi (b) variabel kepuasan kerja sebesar 0,258 bernilai positif artinya terdapat pengaruh positif antara kepuasan kerja dengan kinerja karyawan. Pengaruh positif dapat berarti semakin tinggi kepuasam kerja maka akan semakin tinggi pula kinerja karyawan.

\section{Uji Hipotesis (Uji t)}

Uji t untuk mengetahui pengaruh variabel independen terhadap variabel dependen, apakah pengaruhnya signifikan atau tidak.Tabel dibawah ini merupakan hasil uji t antara variabel Reputasi Koperasi terhadap Kepercayaan Anggota Koperasi :

Tabel 4. Hasil Uji Hipotesis (Uji t)

\begin{tabular}{|l|c|c|c|c|c|}
\hline \multicolumn{5}{|c|}{ Coefficients $^{\text {a }}$} \\
\hline Model & \multicolumn{2}{|c|}{$\begin{array}{c}\text { Unstandardized } \\
\text { Coefficients }\end{array}$} & $\begin{array}{c}\text { Standardized } \\
\text { Coefficients }\end{array}$ & T & Sig. \\
\cline { 2 - 4 } & B & Std. Error & Beta & \\
\hline
\end{tabular}




\begin{tabular}{|l|l|r|r|r|r|l|}
\hline 1 & (Constant) & 10,839 & 1,046 & & 10,359 &, 000 \\
\cline { 2 - 7 } & Reputasi &, 258 &, 094 &, 397 & 2,733 &, 009 \\
\hline
\end{tabular}

a. Dependent Variable: kepercayaan

Berdasarkan hasil uji hipotesis dengan uji t, diperoleh thitung dari variabel reputasi sebesar 10,359. Kemudian nilai tabel dapat dicari pada tabel statistik dengan signifikansi $5 \%$ dengan dk $=\mathrm{n}-\mathrm{k}-1$ atau $\mathrm{dk}=42-1-1=40$, maka didapat nilai tabel sebesar 2,021. Dengan demikian,

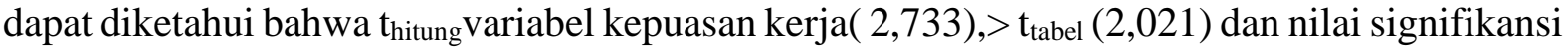
yang diperoleh sebesar $0,000<\alpha=0,05$. Sehingga dapat disimpulkan bahwa, $\mathrm{H}_{0}$ ditolak dan $\mathrm{H}_{\mathrm{a}}$ diterima yang artinya kepuasan kerja berpengaruh positif dan signfikan terhadap Anggota Koperasi.

\section{Uji Koefisien Determinasi}

Analisis Koefisien Determinasi $\left(\mathrm{R}^{2}\right)$ digunakan untuk mengatur seberapa besar kemampuan suatu model menerangkan variasi variabel dependen. Di bawah ini disajikan hasil perhitungan uji koefisien determinasi antara variabel kepuasan kerja terhadap kinerja karyawan, yaitu sebagaiberikut:

Tabel 5. Hasil Uji Koefisien Determinasi

\begin{tabular}{|l|r|r|r|r|}
\hline \multicolumn{5}{|c|}{ Model Summary } \\
\hline Model & \multicolumn{1}{|c|}{ R } & R Square & Adjusted R Square & Std. Error of the Estimate \\
\hline 1 &, $397^{\mathrm{a}}$ &, 157 &, 136 &, 52284 \\
\hline
\end{tabular}

a. Predictors: (Constant), reputasi

Tabel 5.1 Interval Koefisien Korelasi

\begin{tabular}{|c|c|}
\hline Interval Koefisien & Tingkat Hubungan \\
\hline $0,00-0,19$ & Sangat rendah \\
\hline
\end{tabular}




\begin{tabular}{|c|c|}
\hline $0,20-0,39$ & Rendah \\
\hline $0,40-0,59$ & Cukup Kuat \\
\hline $0,60-0,79$ & Kuat \\
\hline $0,80-1,00$ & Sangat Kuat \\
\hline
\end{tabular}

Sumber : Statistika untuk penelitian, Sugiyono

Berdasarkan hasil perhitungan pada Tabel 4.25 di atas, nilai koefisien korelasi sebesar $0,397 » 0,40$ terletak di antara 0,40-0,59. Menurut pedoman interpretasi koefisien korelasi pada Tabel 4.25, nilai tersebut memiliki tingkat hubungan yang cukup kuat. Dengan kata lain, variabel Reputasi pada KSU Tandangsari dengan variabel Kepercayaan Anggota memiliki hubungan atau korelasi yang cukup kuat.

Kemudian diperoleh juga nilai koefisien determinasi sebesar 0.157 x $100 \%=15,7 \%$. Hal ini berarti $15,7 \%$ variabel dependen yaitu Reputasi pada KSU Tandangsari dipengaruhi oleh variabel independen yaitu kepercayaan Anggota. Sedangkan 84,3\% sisanya dipengaruhi oleh variabel-variabel lainnya yang tidak diteliti dalam penelitian ini.

\section{Pembahasan}

Hasil penelitian menunjukkan bahwa Reputasi Koperasi pada KSU Tandangsari berpengaruh positif dan signifikan terhadap Kepercayaan Anggota. Hal tersebut berarti apabila Reputasi pada KSU Tandangsari tinggi, maka akan meningkatkan Kepercayaan Anggota. Hal ini diperkuat dan didukung oleh hasil uji t yang menghasilkan nilai t-hitung lebih besar dati ttabel ( 2,733),> ttabel $(2,021)$ yang artinya hubungan antara Reputasi dan Kepercayaan berpengaruh positif.

\section{Kesimpulan dan Keterbatasan Penelitian}

Penelitian ini dilakukan dengan 42 anggota sebagai responden.. Variabel indipenden pada penelitian ini adalah reputasi sedangkan kepercayaan sebagai variabel dependen. Dari beberapa definisi yang telah dipaparkan, dapat disimpulkan bahwa Reputasi merupakan suatu nilai yang diberikan kepada individu, sedangkan kepercayaan rasa percaya diri seseorang yang ditemukan berdasarkan hasrat dari orang lain daripada kekuatan dirinya.

Peneliti melakukan analisis data yang dikumpulkan melalui kuesioner, berdasarkan penelitian yang dilakukan dan pembahasan yang telah dipaparkan, maka dapat disimpulkan dari hasil penelitian menunjukkan: 
Bahwa $\mathrm{H}_{0}$ ditolak dan $\mathrm{H}_{1}$ diterima yang artinya Reputasi Koperasi berpengaruh positif dan signfikan terhadap Kepercayaan Anggota. Pengaruh positif dapat berarti semakin tinggi Reputasi maka akan semakin tinggi pula Kepercayaan Anggota. Selain itu, variabel Reputasi pada KSU Tandangsari dengan variabel Kepercayaan Anggota pada KSU Tandangsari memiliki hubungan atau korelasi yang cukup kuat dimana 15,7\% variabel.

\section{Keterbatasan Penelitian}

Penelitian ini memiliki beberapa keterbatasan, diantaranya adalah sebagai berikut:

1. Penelitian ini dilakukan pada satu jenis usaha ternak sapi di Koperasi KSU TandangSari Sumedang saja sehingga tidak dapat membandingkan hasil penelitian yang telah diperoleh. Untuk penelitian selanjutnya akan lebih baik jika menggunakan dua atau lebih jenis usaha di Koperasi KSU TandangSari Sumedang sebagai objek penelitian, sehingga dapat membandingkan pengaruh variabel independen terhadap variabel dependen antara satu jenis usaha di Koperasi KSU TandangSari Sumedang dengan usaha lainya.

2. Fokus penelitian hanya terpusat pada Anggota Peternak saja. Untuk penelitian selanjutnya akan lebih baik jika menggunakan lebih dari satu jenis usaha di Koperasi KSU TandangSari Sumedang dengan usaha lainya

3. Adanya lima pilihan jawaban kuesioner membuat para responden cenderung menjawab netral ketika

4. Merasa tidak setuju dengan pernyataan yang ada, sehinnga jawaban yang diperoleh cenderung kurang akurat. Untuk penelitian selanjutnya akan lebih baik jika menggunakan empat pilihan jawaban pada kuesioner dengan mengganti dari jawaba Ya atau Tidak, sehinnga jawaban yang diperoleh cenderung kurang akurat.

\section{DAFTAR PUSTAKA}

Sugiyono (2016). Metode Penelitian Kuantitatif, Kualitatif, dan R\&D. Bandung : Penerbit Alfabeta

M. Suparmoko. (1984). Metodologi Penelitian Praktis . Yogyakarta : Penerbit BPFE

Republik Indonesia. (1992). Undang - Undang Perkoperasian Nomer 25 Tahun 1992

Sudjana. (2005). Metode Statistika. Bandung : Tarsito

Laporan RAT KSU Tandangsari (2018)

Moch. Makin. (2011). Tata Laksana Peternakan Sapi Perah, Yogyakarta: Graha Ilmu

Ramudi Arifin. (2013). Koperasi Sebagai Perusahaan. Sumedang : IKOPIN Press

Sudjana. (2005). Metoda Statistika. Bandung: Tarsito 
Muchadarsyah Sinungan. (2003). Produktivitas apa dan bagaimana. Jakarta: Bumi Aksara Alfred Hanel (2005). Organisasi Koperasi. Yogyakarta: Graha Ilmu

Ika et al. (2015). Pengaruh tingkat kepercayaan, bagi hasil,kesesuaian hukum syariah, reputasi bank dan perolehan informasi terhadap keinginan menambah tabungan mudharabah di Bank Rakyat Indonesia syariah Cabang Jember. Journal of Accounting, 9.

Z Ulchatab. (2014). Pengaruh reputasi koperasi dan kepercayaan anggota terhadap loyalitas anggota koperasi pegawai republik indonesia (KPRI) guru sekolah dasar di kota Tanjungpinang. Journal of management, 100.

Dindin Wahidin. (2015). Analisis faktor-faktor yang mempengaruhi produktifitas susu sapi perah pada peternak KUD Sarwa Mukti. Jurnal skripsi, 